\title{
Highly-Accurate Machining by Linear Motor Drive Wire EDM
}

\author{
Makoto SUGAI \\ (Received August 13, 2001)
}

*Sodick Co., Ltd. / Technology Supervising Department, Yokohama, Kanagawa 224-8522, Japan

\section{INTRODUCTION}

Wire Electrical Discharge Machine is the indispensable machining tool in mold and die making. Particularly in die making for stamping machines, Wire EDM plays the vital role, without which manufacturing of highly-precise die can hardly be achieved. As die for smaller and lightweight parts manufacturing is requiring more precision than ever, urgent demand for Wire EDM with even higher accuracy has been rising.

This paper discusses the essential factors for EDM to achieve highly accurate machining and introduces its machining samples.

\section{ESSENTIAL FACTORS FOR ACCURATE EDM MACHINING}

2.1 Enhancing Dynamic Accuracy by Linear Motor

Highly precise EDM machining requires highly accurate $\mathrm{X}-\mathrm{Y}$ table. Conventional X-Y table needs to convert rotary movement into linear movement through ball screw mechanism. Under ball screw mechanism, repetitive back and forth movement, where direction of movement is reversed, causes backlash and stick-motion. It in turn causes delay in axis movement and position error, which greatly impairs machining accuracy.

On the other hand, linear motor drive X-Y table can achieve highly precise axis movement as no backlash nor stick-motion derived from ball screw mechanism occurs on linear motor drive system. With no typical error caused by backlash and stick-motion around where direction of axis movement is reversed, linear motor drive X-Y table can achieve the movement with excellent dynamic accuracy.

\subsection{Dielectric Fluid and Spark Generator}

Deionized water or oil is used as dielectric fluid for Wire EDM machining. For fine machining and high quality machining, oil based dielectric fluid is the most desirable since its electrical insulation properties does not change in any circumstances. Changes in electrical insulation properties of dielectric fluid cause changes in machining gap, which severely impairs machining accuracy. When deionized water is used as dielectric fluid, alternative pulse is applied for machining. Alternative pulse can effectively prevent electric-chemical corrosion as well as changes in machining gap.

\subsection{Application of Materials with Less Thermal Expansion}

Thermal change in the environment where the machine is installed is one of the major factors in deterioration of machining accuracy.

Application of ceramic materials for main parts such as lower guide arm, platen as well as work stand can make it possible to reduce thermal expansion. As ceramic has higher electrical insulation property, fine electric discharge energy can be well applied to electric discharge gap in fine-finish and superfine-finish machining.

\section{MACHINING SAMPLES}

\subsection{Roundness}

Die making for connection parts of optical fiber cables requires extremely high machining accuracy. An error of $1 \mu \mathrm{m}$ in positioning accuracy and roundness is hardly acceptable.

Fig. 1 shows the machining samples of $\phi 10$ $\mathrm{mm}$ on SKD11 workpiece with thickness of $10 \mathrm{~mm}$. As it successfully achieved $0.43 \mu \mathrm{m}$ of roundness, required accuracy of less than $1 \mu \mathrm{m}$ of roundness can be fully satisfied.

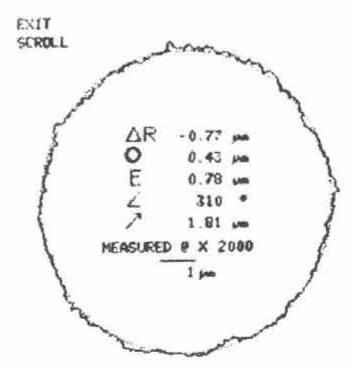

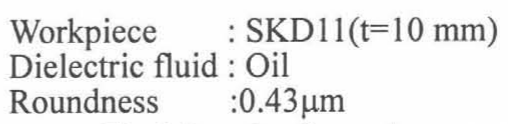

Fig.1 Result of roundness machining 


\subsection{Narrow-Pitch Combination Punch}

Fig.2 shows the machining sample of combination punch with $0.2 \mathrm{~mm}$ pitch, which is identical to Tie-Bar Cut die for IC lead frame. It obtained $\pm 1.0 \mu \mathrm{m}$ machining accuracy and $0.65 \mu \mathrm{m}$ Ry surface roughness by using tungsten wire with $\phi 0.05 \mathrm{~mm}$. Since Oil was used for dielectric fluid, embrittlement due to electro-chemical corrosion did not occur.

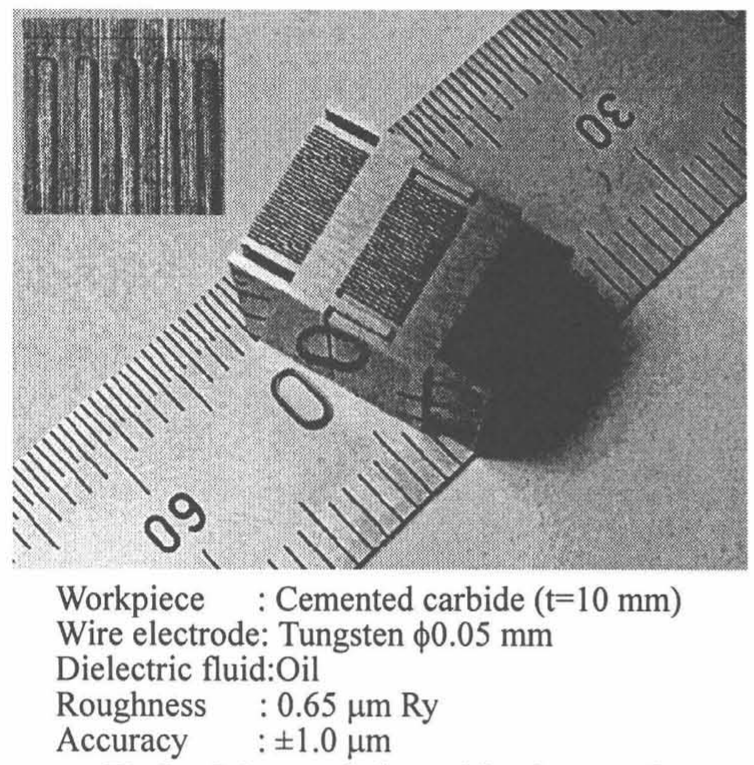

Fig.2 $0.2 \mathrm{~mm}$-pitch combination punch

\subsection{Superfine-Finish under Deionized Water Machining}

Fig.3 shows the sample of superfine-finish machining under deionized water as dielectric fluid. As alternative pulse was used from rough-machining to finishing, it successfully achieved machining with less electro-chemical corrosion.

\subsection{Superfine-finish Machining of Highly Thick Workpiece}

With conventional EDM, it used to be extremely difficult to obtain satisfactory machining surface on workpiece with thickness of over $60 \mathrm{~mm}$. Fig.4 shows the sample of superfine-finish machining on SKD11 workpiece with thickness of $80 \mathrm{~mm}$. With Linear motor drive Wire EDM, it obtained $0.61 \mu \mathrm{m}$ Ry surface roughness.

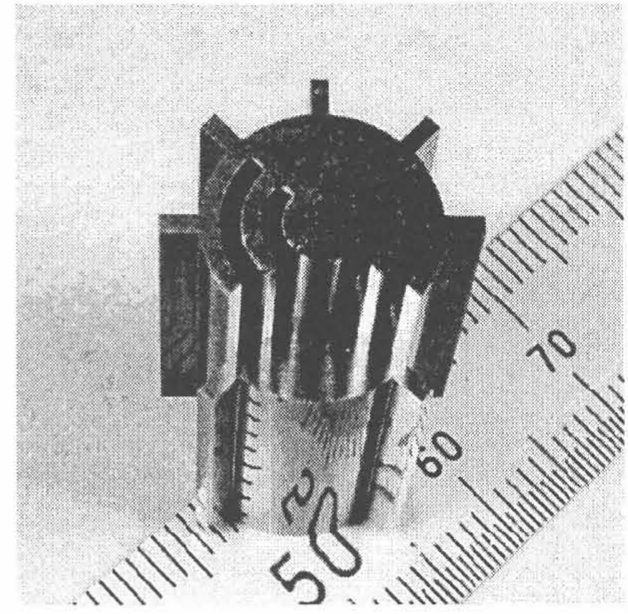

Workpiece : SKD11 $(\mathrm{t}=20 \mathrm{~mm})$

Wire electrode: Brass $\phi 0.2 \mathrm{~mm}$

Dielectric fluid: Deionized Water Roughness : $0.59 \mu \mathrm{m}$ Ry Accuracy $: \pm 1.0 \mu \mathrm{m}$

Fig.3 Superfine-finish under deionized water machining

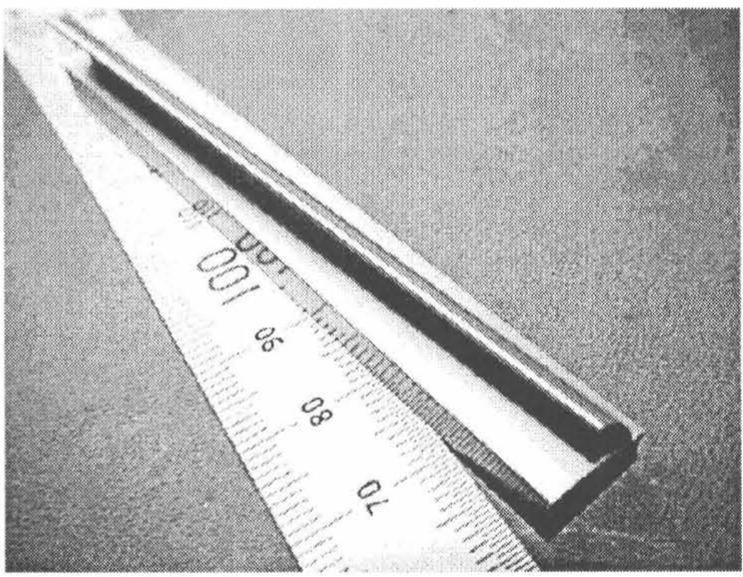

Workpiece : SKD11 $(\mathrm{t}=80 \mathrm{~mm})$

Wire electrode : Brass $\phi 0.2 \mathrm{~mm}$

Dielectric fluid:Oil

Roughness : $0.61 \mu \mathrm{m}$ Ry

Fig.4 Superfine-finish machining of highly thick workpiece

\section{CONCLUSION}

Linear motor drive Wire EDM along with spark generator equipped with superfine-finish circuit can surely meet the growing demand for highly accurate machining. 